\title{
Research on the Relationship between Interpersonal Trust and Implicit Altruism Behavior of High School Students
}

\author{
Xiaorong Gan \\ Department of Psychology \\ Gannan Medical University \\ Ganzhou, China 341000
}

\author{
Wen $\mathrm{Hu}$ \\ Depart ment of Psychology \\ Gannan Medical University \\ Ganzhou, China 341000
}

\begin{abstract}
Interpersonal trust and Altruism behavior are hot issues in the study of human social psychology. By an Interpersonal Trust Scale, the Questionnaire of Explicit Altruism behavior and Implicit Association Test (IAT), 30 highschool students are measured. All data are analyzed with SPSS19.0 and scientific statistical methods. The results indicate that significant implicit altruistic behavior was found, and no correlation was discovered between Interpersonal trust, Explicit Altruism behaviors as well as Implicit Altruistic behaviors.
\end{abstract}

Keywords-high-school students; interpersonal trust; explicit altruism behavior; implicit altruism behavior

\section{INTRODUCTION}

Interpersonal trust influences the evaluation of individual's interpersonal communication and reflects the attitudes of individuals toward humanity. The existing researches show interpersonal trust influences pro-social behaviors. Some scholars address the relations between people giving others a hand and people receiving helps affect the frequency of occurrence of altruis m behavior. Ye Xiaohong have researched the relationship between interpersonal intimacy and implicit altruism behavior. Interpersonal trust is the bas is to establish good interpersonal relationship. As a special psychological state and behavior of human, it plays a vital role in interpers onal communication. A ltruis $m$ behavior is a voluntary behavior without expectation for reward and return. It is the supreme form of pro-social behavior. In this paper, high school students are research object. The empirical research method is used to discuss the relationship between interpersonal trust and altruism behavior.

\section{OBJECT S AND METHODS}

\section{A. Research Object}

Some senior high school has 300 students including 150 male students and 150 female students. All have normal eyesight, know well about basic computer operation and don't participate in similar experiments recently.

\section{B. Research Method}

Experimentation and questionnaire are applied to the research. The former uses IAT (Implicit Association Test) and the latter uses Interpersonal Trust Scale (ITS).

All data are analyzed with SPSS 19.0 Chinese version.

\section{RESEARCH RESULT S}

\section{A. Effect Size of Implicit Altruism Behavior}

The analysis result of implicit altru is $\mathrm{m}$ behavior is shown in "Table I".

TABLE I. REACTION TIME AND EFFECT SIZE OFTESTED IAT

\begin{tabular}{llllll}
\hline & \multicolumn{1}{c}{$\begin{array}{c}\text { Compatible } \\
\text { connection task }\end{array}$} & \multicolumn{2}{c}{$\begin{array}{c}\text { Incompatible } \\
\text { connection task }\end{array}$} & $\begin{array}{c}\text { IAT effect } \\
\text { size }\end{array}$ \\
\cline { 2 - 6 } & $\mathrm{M}$ & $\mathrm{SD}$ & $\mathrm{M}$ & $\mathrm{SD}$ & $\begin{array}{l}\text { Incompatible } \\
\text { compatible }\end{array}$ \\
\hline $\begin{array}{l}\text { Reaction } \\
\text { time }\end{array}$ & 742.885 & 135.823 & 1063.433 & 268.552 & 320.548 \\
Log Koc & 2.864 & .076 & 3.013 & .112 & 2.544 \\
\hline $\begin{array}{l}\text { Note: Reaction time (unit: millisecond) and } \log \text { koc (lg function with 10 as the base number) of } \\
\text { data in the table }\end{array}$
\end{tabular}

Conduct pared-samples $\mathrm{T}$ test for reaction times of compatible task and incompatible task $(\mathrm{t}=6.293$, df $=24$, $\mathrm{p}=0.000$ ). The reaction times of them are obviously different; the results are shown in "Table II".

TABLE II. PARED-SAMPLES T TESTOF IAT EFFECT SIZE (LOG KoC)

\begin{tabular}{lcccc}
\hline & \multicolumn{1}{c}{ T } & df & Sig(2-tailed) \\
\hline Reaction time & 6.293 & 24 & $0.000^{* *}$ \\
Log Koc & 6.711 & 24 & $0.000^{* *}$ \\
\hline \multicolumn{2}{c}{ Note $: \mathrm{p}<0.05^{*} ; \mathrm{p}<0.01^{* *}$} & &
\end{tabular}

The statistic analysis of mean reaction time and $\log$ koc of compatible connection task and incompatible connection task shows obvious IAT effect. The students tested react faster in compatible connection task than incompatible connection task. Therefore, high school students tested in the experiment have obvious tendency of implicit altruism attitude. The altruism attitudes of the high school students sample are automatic. 


\section{B. Relationship between Implicit Altruism Behavior and Explicit Altruism Behavior}

Carry out Pearson analys is for IAT effect size and scores of "explicit altruism behavior questionnaire" to compare the relationship between implicit altruis $m$ behavior and explicit altruism behavior. The results are shown in "Table III".

TABLE III. RELATIONSHIP BETWEEN IMPLICIT AL TRUISM BEHAVIOR AND EXPLICIT ALTRUISM BEHAVIOR

\begin{tabular}{llll}
\hline & \multicolumn{1}{c}{$\mathbf{R}$} & $\mathbf{N}$ & Sig.(2-tailed) \\
\hline IAT effect size & .144 & 25 & .492 \\
Log Koc & -.091 & 25 & .702 \\
\hline
\end{tabular}

The correlation coefficient between IAT reaction time and effect size and scores of explicit altruis $m$ behavior $r=0.144$, $\mathrm{p}=0.492, \mathrm{p}>0.05$, without obvious correlation; the correlation coefficient between $\log$ koc and score of explicit altruism behavior $\mathrm{r}=-0.091, \mathrm{p}=0.702, \mathrm{p}>0.05$, without obvious correlation. It shows implicit altruis $\mathrm{m}$ behavior and explicit altruism behavior have no obvious correlation. Implicit altruism behavior is stable and separate from explicit altru is $m$ behavior.

\section{The Relationship between Interpersonal Trust and Implicit and Explicit Altruism Behaviors}

Pearson analysis is adopted for compare the relationship between interpersonal trust and implicit altruism behavior and explicit altru ism behavior respectively, in order to discuss the relationship between interpersonal trust and implicit and explicit altruism behaviors. The results are shown in "Table IV".

TABLE IV. THE RELATIONSHIP BETWEEN INTERPERSONAL TRUST AND IMPLICIT AND EXPLICIT ALTRUISM BEHAVIORS

\begin{tabular}{lccc}
\hline & $\mathbf{R}$ & $\mathbf{N}$ & Sig.(2-tailed) \\
\hline Implicit altruism behavior & -.323 & 25 & .116 \\
Explicit altruism behavior & -.234 & 25 & .260 \\
\hline
\end{tabular}

Statistic data about relationship between implicit altruis $\mathrm{m}$ and explicit altruism behaviors and interpersonal trust are shown in table 4 . The results show the correlation between implicit altruism and explicit altruis $\mathrm{m}$ behaviors and interpersonal trust is not obvious.

\section{DISCUSSION}

\section{A. Implicitness of Altruism Behavior Tendency}

The research indicates the altruism behavior of high school students has obvious IAT effect and implicit tendency. Individuals are faster in connection of words about selfconcept and altruism than that of self-concept and non altruism. The tendency is the same among male and female students. It shows in implicit cognition, the altruism tendency of students tested is automatic.

\section{B. Relationship between Interpersonal Trust and Implicit and Explicit Altruism Behaviors}

In this research, the interpersonal trust has no relationship with implicit and explicit altruism behaviors. It fails to conform to the research results of Yu Yan on relationship between interpersonal trust and implicit and explicit altruism behaviors. In Yu Yan's research, implicit altruism behaviors don't relate to interpersonal trust but explicit altruism behaviors have positive correlation with interpersonal trust. Furthermore, interpersonal trust can foresee explicit altru is m behaviors.

\section{CONCLUSION}

The results show: The altruism behavior of high school students has automatic implicit tendency. No significant correlations exist between interpersonal trust and explicit and implicit altruism behaviors.

\section{REFERENCES}

[1] Jiang Da, Wang Xinrui, Fu Li, Zhou Renlai. Experiment Research of Implicit Altruism Behavior [J], Psychological Science, 2008, 31(1): 7982

[2] Yang Zhiliang, Sun Lianrong. Review on Research and Development of Implicit Social Cognition [J], Psychological Exploration, 2009, 4 (29): 11-14

[3] Jiang Da, Wang Xinrui, Fu Li, Zhou Renlai. Experiment Research of Implicit Altruism Behavior [J], Psychological Science, 2008, 31(1): 79 82

[4] Zeng Panpan, Yu Guoliang, Lin Chongde. New Perspective of Research on Pro-social Behavior [J], Education Science, 2011, 27 (1): 21-26. 